Bangladesh J. Bot. 49(4): 981-988, 2020 (December)

\title{
VULNERABILITY OF OASIS AGRICULTURE TO SANDSTORM DISASTERS IN XINJIANG, CHINA
}

\author{
Jingmin GaO ${ }^{*}{ }^{1}$, Dongxu Chen $^{2}$ and MaimaitiJiang Saitiniyazi \\ Binjiang College, Nanjing University of Information Science \& Technology, \\ Nanjing, 210044, China \\ Keywords: Vulnerability, Adaptability, Oasis agriculture, Sandstorm disasters
}

\begin{abstract}
A vulnerability assessment index system and model for oasis agriculture to sandstorm disaster had been constructed. The concept was based on the characteristics of oasis agriculture, from the view of comprehensive disaster reduction and regional sustainable development. Seven main oasis agricultural regions in Xinjiang, China in 1980s, 1990s and 2000s were considered. Focusing on the sensitivity of regional hazardformative environments and the adaptability of sandstorm disaster affected bodies, the vulnerability of oasis agriculture was assessed. The results showed that the vulnerability of oasis agriculture to sandstorm disaster changes in different periods and is mainly affected by sensitivity of climate and adaptability of local agricultural conditions. During the past three decades, the sensitivity has been enhanced in some regions, but the vulnerability of the region has not been significantly reduced because of the enhancement of human adaptability.
\end{abstract}

\section{Introduction}

Xinjiang lies in the north of the People's Republic of China and is a part of Central Asia, prone to sandstorms. The formation and development of sandstorms in Xinjiang are directly affected by the local climate and environmental conditions ( $\mathrm{Gu}$ et al. 2002). Sandstorms are harmful to human living condition and social economy. So, people are increasingly aware that the effects of sandstorm are not only a serious meteorological disaster, but also to the ecological and environmental problems which should not be ignored. In recent years, sandstorm disasters have become a research hotspot in the fields of geosciences, resources and environmental sciences. Oasis agriculture, also known as oasis irrigation agriculture and fertile oasis agriculture (Huang et al. 2014). It refers to the agriculture, distributed in arid desert areas with water sources for irrigation. Throughout the world, oasis agriculture is mainly distributed in West Asia, Midwest of the United States of America (USA), Central Asia of Russia, Sahara and North Africa, Xinjiang and Hexi Corridor of Gansu Province of China.

Disaster risk assessment is one of the important ways to effectively prevent and mitigate disasters (Shi 2002). A number of research work have so far been done on the occurrence and development of sand-dust storm disasters and their risk assessment (Sum et al. 2001, Orlovsky et al. 2005). Disaster risk assessment is a process of comprehensive analysis and decision-making on the analysis of natural and social attributes of disasters (Gao 2016). Difficulty to disaster risk assessment comes not only from the analysis and prediction of disaster-causing factors and disaster occurring environment, but also from the specificity and uncertainty of sandstorm affected bodies in social attributes (Hao et al. 2012, Shang 2013). At present, there are many studies on the natural attributes to sandstorm disasters in China, and many progresses have been made (Goudie 1983, Qian et al. 2004, Wang et al. 2004, Zhang et al. 2005). However, the research on vulnera-

*Author for correspondence: <gjm690717@163.com>. ${ }^{1}$ Jiangsu Key Laboratory of Agricultural Meteorology, Nanjing University of Information Science \& Technology, Nanjing, 210044, China. ${ }^{2}$ Nanjing University of Information Science \& Technology, Nanjing, 210044, China. 
bility of sandstorm disaster from the perspective of social attributes is relatively rare (Hao and Mustapha 2012). Actually, the vulnerability is an important part of disaster assessment (Shang 2013). The disaster risk assessment and management can be targeted more efficiently only by fully considering the particularity and vulnerability of different disaster affected bodies (e.g., oasis agriculture). To it combining the risk of disaster-causing factors, the sensitivity of disasterpregnant environment could be understood. This ultimately provides a scientific basis for local governments to make disaster prevention and mitigation plans (Gao and Sang 2017).

Oasis agriculture is the pillar industry of Xinjiang's economy. More than $95 \%$ of the population and total agricultural production value are concentrated in the oasis which only accounts for $8.2 \%$ of Xinjiang's land area. The larger oasis is more than 100 with area of $1,000-1,200 \mathrm{~km}^{2}$, mainly scattered in the margins of Tarim and Junggar basins. Sandstorm disasters in oasis agricultural areas are characterized by large losses, sudden occurrence, high severity and high frequency.

The specific objectives of this study were - to construct an index system and model for assessing the vulnerability of oasis agriculture, to analyze the influence mechanism of the disaster affected bodies in the formation of sandstorm disasters and to evaluate the whole from the perspective of natural and social attributes in oasis agricultural areas of Xinjiang.

\section{Materials and Methods}

The study area included were seven oasis agricultural areas in Shihezi, Aksu, Kuqa, Kurla, Kashgar, Shache and Hetian of Xinjiang. The meteorological data used in this research were obtained from the surface meteorological observation data and dust weather data set from 1980 2010. The data were provided by China Meteorological Science Data Sharing Service Network. The adaptability evaluation data mainly sourced from the social economic survey database and agricultural statistical yearbook of Xinjiang, Uygur autonomous region.

The corresponding indicators from two aspects of sensitivity and adaptability to determine the evaluation indicators suitable for Xinjiang oasis agriculture was selected and the disaster assessment index system was constructed. A database was created by using the data on meteorology, socio-economic information, agricultural output, oasis geographical location and other relevant information. The weight of each index is determined by Analytic Hierarchy Process method (AHP). The importance of each index in the evaluation index system is confirmed. Based on this, the vulnerability model of oasis agriculture to sandstorm disaster was constructed and the vulnerability assessment was carried out.

Model construction principles were based on the agricultural production adaptation, sustainable development of regional oasis agricultural economy and stability of oasis agro-ecosystem. Finally, the vulnerability evaluation index of dust storm disaster in agricultural oasis was selected and determined by using multi-index evaluation index system and combining expert experience.

Sensitivity index includes climate factors, environ-mental factors, soil and topographic factors (Table 1). Among them, climate factors include: (1) Heat resources i.e., the annual accumulated temperature greater than or equal to $0^{\circ} \mathrm{C}$. It is an index to measure the total heat of a region, which is of great significance in agricultural production. Heat resources not only directly affect the oasis agricultural, but also affect the vulnerability of oasis agriculture through the coordination with water resources, vegetation distribution types and distribution density. (2) Windy days and average wind speed mean strong wind makes dust fly and diffuse. A lot of sand and dust shade the sun, wipe away fertile soil, seeds and seedlings from farmland, and affect oasis agriculture. The strong wind will also aggravate the wind erosion and desertification of the surface soil. It will also 
cover the thick sand and dust on the plant leaves, affect the normal photosynthesis, and cause crop yield reduction. (3) Aridity index i.e., an index describing climate dryness. It is the ratio of potential evapotranspiration to precipitation. It reflects the income and expenditure of water in a certain place during a certain period. (4) Water, is a very important factor that restricts the formation and evolution of vulnerable oasis agriculture. It functions through the amount and the stability of precipitation, the relationship between evapotranspiration and precipitation, the rate of runoff changes and the salinity of groundwater. (5) Dust storm duration, it is calculated according to the start and stop time of each dust storm process. (6) Relative humidity, its increase has a significant inhibitory effect on the occurrence and development of local dust weather.

Table 1. Sensitivity and adaptability index of agricultural oasis to sandstorm disasters.

\begin{tabular}{|c|c|c|c|}
\hline \multicolumn{2}{|l|}{ Target level } & \multicolumn{2}{|l|}{ Sensitivity indicators } \\
\hline Criterion level & A Climate indicators & B Environmental indicators & C Soil indicators \\
\hline \multirow[t]{9}{*}{ Indicator level } & A1 Precipitation variability & B1 Per capita water resources & C1 Soil moisture \\
\hline & A2 Average annual precipitation & B2 Per capita surface water area & C2 Soil type \\
\hline & A3 Aridity index & B3 Distance from sand areas & C3 Land use types \\
\hline & A4 Visibility & B4 Land bareness & C4 Surface sand \\
\hline & $\begin{array}{l}\text { A5 Accumulated temperature > } \\
=0^{\circ} \mathrm{C}\end{array}$ & B5 Vegetation coverage & \\
\hline & A6 Dust storm duration & B6 Vegetation type & \\
\hline & A7 Wind days & B7 Desertification degree & \\
\hline & A8 Relative humidity & & \\
\hline & A9 Average wind speed & & \\
\hline Target level & Adaptability indicators & & \\
\hline Criterion level & $\begin{array}{l}\text { D Socio-economic } \\
\text { Conditions }\end{array}$ & $\begin{array}{l}\text { E Resources and environment } \\
\text { conditions }\end{array}$ & $\begin{array}{l}\text { F Environmental } \\
\text { governance } \\
\text { conditions }\end{array}$ \\
\hline \multirow[t]{7}{*}{ Indicator level } & D1 Population density & E1 Per capita cultivated land area & $\begin{array}{l}\text { F1 Control rate of } \\
\text { degraded land }\end{array}$ \\
\hline & D2 Per capita GDP & E2 Crop planting area & \\
\hline & $\begin{array}{l}\text { D3 Proportion of non- } \\
\text { agricultural population }\end{array}$ & E3 Area of plastic greenhouse & \\
\hline & D4 Poverty ratio & & \\
\hline & D5 Input rate for disaster relief & & \\
\hline & D6 Population growth rate & & \\
\hline & $\begin{array}{l}\text { D7 Farmers' per capita net } \\
\text { income }\end{array}$ & & \\
\hline
\end{tabular}

Environmental sensitive indicators include: (1) Water resources indicators, i.e., per capita water resources and surface water area. (2) Vegetation index, i.e., vegetation coverage. It is one of the main factors affecting soil erosion. Therefore, vegetation coverage is also one of the important environmental sensitive indicators. Different vegetation types have different sensitivity to climate change. Previous studies have shown that there is a good correlation between vegetation coverage and vulnerability (Gu et al. 2002). (3) Desertification index, it is explained as the proportion of desertification land area to total land area. (4) Distance from sand areas, explanation of this factor is - the closer the oasis agricultural area is to the sand areas, the higher its vulnerability. (5) Land bareness, since vegetation can relieve the soil erosion resulted from wind and water, avoid the 
bareness of the surface land and reduce the wind speed through the vegetation coverage on the surface, it has been considered as an important model parameter.

Soil sensitivity indicators: (1) Soil moisture is an important index to measure the dry and wet condition of the land surface. Soil moisture content effects the dust emission and input conditions in the forecasting model systems of dust storm (Gu et al. 2002, Wang et al. 2014). (2) Soil type: different soil types have different intensity in sand-lifting. The content of soil organic matter is directly proportional to the wind erosion resistance of soil. (3) Land use/cover: it affects the characteristics of underlying surface (Hao et al. 2018), and the ability of soil wind erosion resistance. This parameter varies greatly with different surface characteristics and coverage degree having different impacts on the occurrence of sandstorm disasters. (4) Surface sand: it is the material object of the sandstorm disasters. The sand sources of sandstorm disasters mainly include two aspects: local and exotic.

The factors affecting the adaptability to sandstorm disasters mainly involve local technical, managerial, economic and cultural level of the region. The adaptability indicators selected here include socio-economic conditions, resources and conditions of environment and environmental governance (Table 1).

Among the indicators of social and economic conditions, population density reflects the carrying capacity. Over-high population density will aggravate the ecological vulnerability. Therefore, the total population density and industrial population density are selected as two indicators. The higher the net income per capita and GDP per capita of farmers, the stronger their ability to resist natural disasters and the stronger their adaptability. The proportion of nonagricultural population reflects the diversification of industrial structure. Compared with single industrial structure, multi-industrial structure has stronger ability to adapt to sandstorm disasters. The natural growth rate of population is inversely proportional to the adaptability. Over-rapid population growth will exceed its carrying capacity and aggravate the vulnerability of oasis agriculture. The larger the proportion of the poor population, the weaker the ability to resist natural disasters, and the higher the input rate to resist natural disasters, the smaller the losses caused by disasters and the stronger the adaptability.

Among the indicators of resource and environment conditions, the per capita cultivated land area reflects the amount of land resources space occupied by each individual. It is an important material basis for the local social and economic development. It reflects the development capacity and potential of regional social economy, as well as the adaptability to adverse environmental changes. The environmental governance conditions include environmental protection and ecological conservation. All these reflect the ability of the region to resist natural disasters and to control unfavorable environmental conditions. Here the control rate of degraded desertified cultivated land is chosen to reflect its adaptability to sandstorm disasters.

In the generalized vulnerability assessment system (Shi 2002), the combination of disasterprone environment (natural and human environment), disaster-affecting system (socio-economic system) and disaster-prone region or period will inevitably lead to a higher vulnerability level of disaster system. According to this theory, the vulnerability of sandstorm disasters is considered in two aspects. One is the environmental sensitivity of sandstorm disasters, the other is the adaptability of oasis agriculture. Based on this, the vulnerability evaluation model of oasis agriculture to sandstorm disasters is constructed as follows:

$V_{p}{ }^{*}=V_{p 1} / V_{p 2}$

$V_{p}{ }^{*}$ is vulnerability, $V_{p S}$ is sensitivity and $V_{p A}$ is adaptability of oasis agriculture.

The sensitivity index $V_{p S}$ can be calculated as follows:

$$
V_{p S}=\sum X_{i} \times W_{i}
$$


where, $X_{i}$ is the sensitivity value of the $i^{\text {th }}$ index, and $W_{i}$ is the weight of the $i^{\text {th }}$ index.

The adaptability index $V_{p A}$ can be calculated:

$V_{p \mathrm{~A}}=\sum Y_{i} \times W_{i}$

where, $Y_{i}$ is the adaptability value of the $i^{\text {th }}$ index.

Normalization using Eq. (4):

$$
V_{p}=\left(V_{p}^{*}-\min V_{p}^{*}\right) /\left(\max V_{p}^{*}-\min V_{p}^{*}\right) \times 100
$$

The $\max V_{p}$ and $\min V_{p}^{*}$ in Eq. (4) are maximum and minimum values of the corresponding indicators in the assessment region.

\section{Results and Discussion}

According to the characteristics of oasis agricultural area in Xinjiang and considering the availability and practicability of data in the study area useful sensitivity indices were selected. These are the precipitation variability, annual average precipitation; visibility, annual mean temperature; duration of sandstorm, wind days; relative humidity and average wind speed. Population density, per capita GDP, proportion of non-agricultural population, population growth rate and per capita net income of farmers are selected as socio-economic adaptability indicators. The total power of agricultural machinery, crop planting area and per capita arable land area are used as adaptability indicators of agricultural production conditions. Using the above mentioned evaluation model, vulnerability of seven oasis agricultural areas in Xinjiang was carried out.

Table 2. Hierarchical single ranking and consistency test of sensitivity indicators and adaptability indicators (Socio-economic conditions and agricultural production conditions).

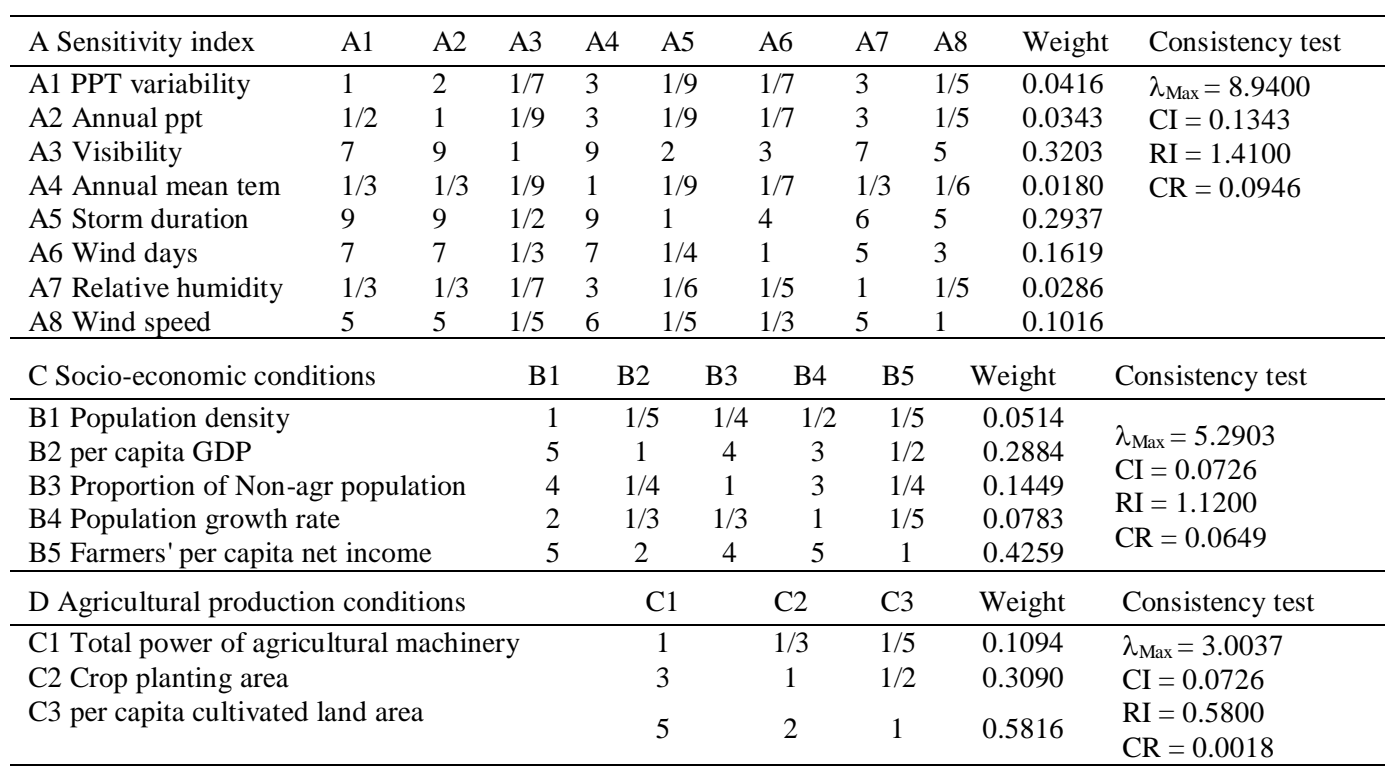

The weight of vulnerability index is determined by AHP hierarchy method. A judgment matrix is established by comparing the importance of two indicators (Tables 2 - 3). After determining the classification scheme and calculation method of sensitivity index and adaptability index, the classification scheme of vulnerability index can also be determined. The overall evaluation criteria and classification schemes of sensitivity and adaptability indicators are shown in Table 4. 
Table 3. Weights of sensitivity and adaptability indicators.

\begin{tabular}{|c|c|c|c|c|c|c|c|}
\hline $\mathrm{X}$ & Target level & Ser & index & & Adaptabi & index & \\
\hline Y & Criterion level & A Sen & indicators & B Socio & ic conditions & D Agri & al production \\
\hline & & & & & & & \\
\hline & & A2 & 0.0343 & B2 & 0.17304 & $\mathrm{C} 2$ & 0.1236 \\
\hline & & A3 & 0.3203 & B3 & 0.08694 & $\mathrm{C} 3$ & 0.23264 \\
\hline & & A4 & 0.0180 & B4 & 0.04698 & & \\
\hline & & A5 & 0.2937 & B5 & 0.25554 & & \\
\hline & & A6 & 0.1619 & & & & \\
\hline
\end{tabular}

Table 4. Level of Sensitivity and adaptability Indicators.

\begin{tabular}{llllllllll}
\hline Levels & Sensitivity & $\mathrm{A} 1 / \%$ & $\mathrm{~A} 2 / \mathrm{mm}$ & $\mathrm{A} 3 / \mathrm{km}$ & $\mathrm{A} 4 /{ }^{\circ} \mathrm{C}$ & $\mathrm{A} 5 / \mathrm{min}$ & $\mathrm{A} 6 / \mathrm{d}$ & $\mathrm{A} 7 / \%$ & $\mathrm{~A} 8 / \mathrm{m} / \mathrm{s}$ \\
\hline 1 & $0-20$ & $<5$ & $>150$ & $>15$ & $<8$ & $<30$ & $<30$ & $>60$ & $<1.3$ \\
2 & $20-40$ & $5-10$ & $150-100$ & $15-10$ & $8-9.5$ & $30-60$ & $30-80$ & $60-55$ & $1.3-1.5$ \\
3 & $40-60$ & $10-15$ & $100-70$ & $10-6$ & $9.5-11$ & $60-90$ & $80-150$ & $55-50$ & $1.5-1.8$ \\
4 & $60-80$ & $15-20$ & $70-50$ & $6-3$ & $11-13$ & $90-120$ & $150-250$ & $50-45$ & $1.8-2.1$ \\
5 & $80-100$ & $>20$ & $<50$ & $<3$ & $>13$ & $>120$ & $>250$ & $<45$ & $>2.1$ \\
\hline Levels & Adaptability & $\mathrm{B} 1 / \mathrm{km}^{2}$ & $\mathrm{~B} 2 / \mathrm{Yuan}$ & $\mathrm{B} 3 / \%$ & $\mathrm{~B} 4 / \%$ & $\mathrm{~B} 5 / \mathrm{Yuan}$ & $\mathrm{C} 1 / 10^{7} \mathrm{w}$ & $\mathrm{C} 2 / 10^{3} \mathrm{ha}$ & $\mathrm{C} 3 / \mathrm{Mu}$ \\
\hline 1 & $0-20$ & $>450$ & $<300$ & $<15$ & $>16$ & $<100$ & $<3$ & $<10$ & $<0.5$ \\
2 & $20-40$ & $450-100$ & $300-1000$ & $15-25$ & $16-12$ & $100-500$ & $3-5$ & $10-20$ & $0.5-1$ \\
3 & $40-60$ & $100-50$ & $1000-3000$ & $25-40$ & $12-8$ & $500-1500$ & $5-10$ & $20-50$ & $1-2$ \\
4 & $60-80$ & $50-20$ & $3000-6000$ & $40-60$ & $8-5$ & $1500-3000$ & $10-15$ & $50-100$ & $2-3$ \\
5 & $80-100$ & $<20$ & $>6000$ & $>60$ & $<5$ & $>3000$ & $>15$ & $>100$ & $>3$ \\
\hline
\end{tabular}

Hundred per cent sensitivity/adaptability indicates the highest or most sensitive/adaptability level.

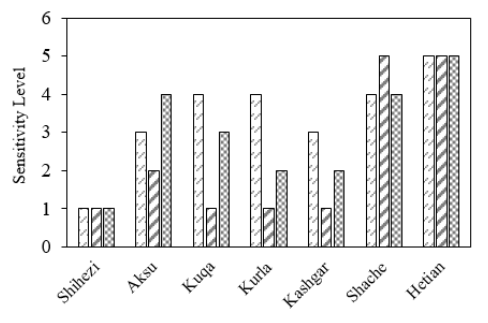

$\square 1980$ s $\square 1990$ s $\square 2000$ s

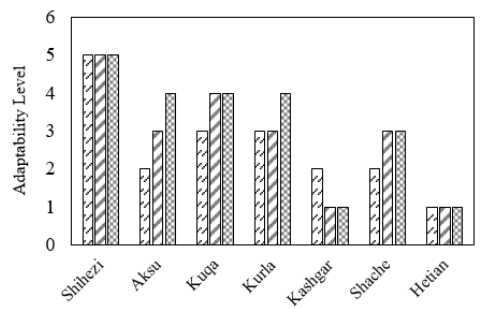

$\square 1980 \mathrm{~s} \square 1990 \mathrm{~s} \square 2000 \mathrm{~s}$

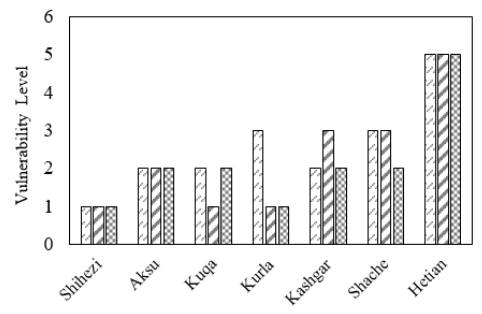

$\square 1980 \mathrm{~s} \square 1990 \mathrm{~s} \square 2000 \mathrm{~s}$

Fig. 1. Sensitivity, adaptability and vulnerability level in three decades in Xinjiang oasis agricultural regions. 
The vulnerability of oasis agriculture to sandstorm disaster showed that the vulnerability of oasis agriculture to dust storm disasters is mainly affected by sensitivity and adaptability. Compared with 1980s, the vulnerability of Kuqa and Kurla in 1990s was weakened, the vulnerability of Kashgar was strengthened, and other regions did not change significantly. Compared with 1990s, the vulnerability of Kashgar and Shache in 2000s was weakened, the vulnerability of Kuqa was strengthened, and other regions did not change significantly. Compared with 1980s, the vulnerability of Kurla and Shache in 2000s was weakened, and other regional changes were not obvious. Generally, Kuqa, Kurla and Shache are the main oasis areas with greater vulnerability changes. As the proportion of non-agricultural population, per capita GDP, net income of farmers and other factors increase, the adaptability is greatly improved in these regions, so the vulnerability of oasis agriculture is weakened (Fig. 1).

This report synthetically considers meteorological factors to construct a sensitive index system, and economic-production-environment factors to construct an adaptive index system. On this basis, a comprehensive vulnerability evaluation system is made. However, due to the limitation of data sources, factors such as distance from the sand area, slope direction, and plastic greenhouse, which could reflect the vulnerability of sandstorm disasters in oasis agricultural areas, have not been taken into account, which may have some impact on the evaluation results.

\section{Acknowledgements}

This work was supported by the National Natural Science Foundation of China (Grant numbers 41977409), and foundation of Binjiang, Nanjing University of Information Science and Technology (2019BJYNK004). The authors acknowledge the China Meteorological Data Service Center (http://data.cma.cn/en) for providing weather observation data.

\section{References}

Gao JM 2016. Analysis and assessment of the risk of snow and freezing disaster in China. Int. J. Disast. Risk Re. 19: 334-340.

Gao JM and Sang YH 2017. Identification and estimation of landslide-debris flow disaster risk in primary and middle school campuses in a mountainous area of southwest China. Int. J. Disast. Risk Re. 25: 60-71.

Goudie AS 1983. Dust storm in space and time. Prog. Phys. Geogr. 7(4): 502-508.

Gu W, Cai XP, Xie F, Li ZJ and Wu XH 2002. Study on relationship between vegetation cover and distribution of days of sandstorm: taking central and western Inner Mongolia for example. J. Adv. Earth Sci. 17(2): 273-277. (In Chinese)

Hao L, Zhang XY and Liu SD 2012. Risk assessment to China's agricultural drought disaster in county unit. Nat. Haz. 61(2): 785-801.

Hao L and Mustapha 2012. Changes of sandstorm occurrence and meteorological impact factors in Xinjiang oasis agricultural area. J. Arid Land Resour. Environ. 26(8): 130-134. (In Chinese)

Hao L, Pan C, Fang D, Zhang XY, Zhou DC, Liu PL, Liu YQ and Sun G 2018. Quantifying the effects of overgrazing on mountainous watershed vegetation dynamics under a changing climate. Sci. Total Environ. 639: $1408-1420$.

Huang CB, Zeng FJ and Lei JQ 2014. Impact of cultivation practices in oasis agriculture on soil fertility dynamics and the relationship with cotton nitrogen-use efficiency in the southern rim of the Tarim basin, Xinjiang, China. Commun. Soil Sci. Plan. 45(20): 2621-2635.

Orlovsky L, Orlovsky N and Durdyev A 2005. Dust storms in Turkmenistan. J. Arid Environ. 60: 87-97.

Qian YB, Wu ZN, Yang Q, Zhang LY and Wang XY. 2004. Ground-surface conditions resulting in sand-dust storms in the south Junggar Basin. Arid Land Geogr. 27(4): 540-542.

Shang YR 2013. Review on concept model of disaster vulnerability. J. Catastrophology 28(1): 112-116. 
Shi PJ 2002. Theory on disaster science and disaster dynamics. J. Nat. Haz. 11(3): 1-9. (In Chinese)

Sun J, Zhang M and Liu T 2001. Spatial and temporal characteristics of dust storms in China and its surrounding regions, 1960-1999: Relations to source area and climate. J. Geophys. Res. Atmos. 106(D10): 10325-10333.

Wang JY, Wei LB, Zhao ZS, Li X and Zhang ZW 2014. The influence of soil moisture content on the numerical simulation of dust storms. Appl. Mech. Mater. 522-524: 235-238.

Wang X, Dong Z, Zhang J and Liu L 2004. Modern dust storms in China: An overview. J. Arid Environ. 58 (4): 559-574.

Zhang L, Ding YH and Ren GY 2005. Variation of dust weather and its climatic attribution analysis in northern part of China. J. Appl. Meteorol. Sci. 16(5): 584-592. (In Chinese).

(Manuscript received on 9 April, 2019; revised on 2 February, 2020) 